\title{
Flowers and a Garden, Children and Games, Laughter and Fun: Unity in Diversity
}

\author{
REINETH PRINSLOO \\ Department of Social Work and Criminology, Faculty of Humanities, University of Pretoria, \\ Pretoria, South Africa \\ JENILEE BOTHA \\ LEE-ANN HUMAN \\ LINDOKUHLE MAPHALALA \\ THATO MASUKU \\ ZIPHO TSHAPELA \\ EVADNÉ VAN DEN BERG \\ University of Pretoria, South Africa, Pretoria, South Africa
}

Social work declares its commitment to respect and valuing human dignity, to acceptance, unconditional positive regard, equity, self-determination, a non-judgmental approach and social justice. When I, as group work professor, entered the third year social work class at the beginning of this year (2015), it was disturbing to see the way that the students divided themselves with regard to culture, language and even age to some extent. After providing an orientation about the content of the module on advanced group work skills, I reflected on what I observed and confronted the students. Being dedicated to teaching sensitivity to diversity, I told the students that I refuse to teach a senior social work student group that is divided and where students do not mingle, bond and integrate.

Consequently, I arranged for a three-hour experiential class the next week, to be held on the university's sports grounds close to our main campus. The aim of the class was to be twofold; firstly, to let the students experience being group members and secondly, to address the issues of division that I observed. Not only should group workers help members to recognize differences and understand them, they should also recognize and understand their own values and differences. Group workers' world views, beliefs and values of group influence their practice. I feel strongly about the fact that a social worker, and especially a 
group worker, has to be aware of his or her own values and perceptions before attempting to engage with others.

The activities that I planned aimed at providing fun and relaxation, yet providing a deep focus on integration of theory and becoming aware of each other. Students had to play with soccer balls, dance to the rhythm of music, do team activities (in united fashion), such as picking up hula-hoops and passing them without breaking a circle held together by holding hands. They played games from their childhood years and they had to teach each other these childhood games. I wanted to take them back to being a child; the place where we are socialized and where family of origin and childhood contexts form current perspectives, values and beliefs.

I witnessed an amazing transformation. Before they realized what was happening, they were asking each other about the origin of the games and they were starting to repeat the instructions in each other's mother tongues, even if pronounced awkwardly. They laughed and I had to ask one of the students who could whistle loudly to get their attention to continue to another exercise. The atmosphere was one of pure bliss! Students who never before communicated did so now. Seventy students danced in harmony as one long train to the songs of different cultural groups.

The last exercise for the day was completing the third year group work class garden on a huge poster. Two students assisted me prior to the class to paint a basic garden with two prominent trees. Every student present at the experiential class had to paint his or her own flower in the garden. They had a choice of paintbrushes and different colors of paint. I commented that the poster painting formed one garden, yet not two of the flowers were the same. The unity in diversity made for one beautiful and color-filled garden in which the students, who were divided before the class commenced, departed as one large bonded 
group. The feedback was amazing. The stories that follow provide a view of the transformation that transpired on that glorious day, from the perspective of six students.

\section{REFLECTIONS}

\section{Jenilee: Nacre is my answer.}

Nacre is my answer. "The answer to what?" one might ask, thereupon I shall elaborate with the utmost of confidence, "the answer to most problems in society!" Group work has proven itself to me in so many ways before and after, but on this specific occasion, I was gleefully aware of how it feels to be a part of the problem, and part of the solution; and as nacre believe, a part of something beautiful.

Nacre is the calcium carbonate layer of silky, luminous and iridescent substance lined on the inside of a pearl-producing oyster. As it happens in nature, as well as in our daily lives, many conflicts arise from the fear of 'something different'. When a grain of sand finds its way through the clasps of an oyster, it moves to stay on the bedded cushion in the middle of the organism where it then causes a discomfort. This strange object is perceived as a threat, and in the process of protecting itself, the oyster will continuously cover the grain of sand with a special substance made out of millions of light reflecting particles. This substance is called nacre, and will be layered over the grain of sand many times until it hardens, which then forms what we know to be as a beautifully valuable pearl.

In my experience, group work is precisely described through this miraculous process that nature has created to turn something problematic into something extraordinary. On this specific occasion, diversity within our class was acting as the grain of sand that has made its way into the hearts of the class members. Differences in culture, appearance and even language created an environment of fear and discomfort. Nationwide, and South Africa in specific, countries have vast varieties of ethnicities, cultural backgrounds and 
religions, which have managed to become a threat to large populations of its inhabitants. This was the student's experience, even within a class dedicated to enhancing equality and acceptance amongst all people.

However, because of group work and the uplifting participation in one glorious morning of genuine Ubuntu (an ancient African word meaning humanity to others'), the discomfort and fear of everything different was challenged and turned into a beautiful product. As with an oyster, the classroom members were exposed to the worlds of others through working together, mutual sharing and going back to the fun activities of youth. The beauty in each culture was found by all, generating layers and layers of team-work until the product was a class full of members with respect for one another and for diversity, as if a precious pearl.

In this world of shifting sands, group work as we experienced it on that morning, was at the heart of a beautiful nacre world.

Lindokuhle: I was no longer standing on my own guarding a tree.

There is absolutely nothing more frustrating to a student than the words "compulsory attendance." We try to avoid taking a shower, dressing up and coming to campus and interacting with people. One can only then imagine the feeling when Prof. Prinsloo informed us that she had planned a joint group activity for our entire class. I try to avoid group activities; I always stick out like a sore thumb or cling to the one person who was brave enough to talk to me first.

I have always known Prof. Prinsloo to be an energetic and an inspirational lecturer. However, I did feel that this time she was just pushing things way too far. I honestly felt race and diversity and unity will always be an issue regardless of the many times we try to 
address it. I always felt it should rather be swept under the carpet and that nobody should talk about it.

The day of our joint class activity came and, as usual, being the social butterfly that she is, my only friend left me standing in the middle of a crowd. Which was really awkward because these are the same people I have attended class with for the past three years and you would think by now we would have gotten to know each other? As I was standing there, I noticed that everyone was clustered in little groups of their close circle of friends until Prof. Prinsloo scattered us around and formed us into different groups. We all stood in awe; giving each other awkward little smiles as we listened to Prof. giving us activity instructions.

It was only at the end of our group exercise that I realized the group dynamics that took place during the activities, including the importance of communication, the emergence of a group leader and the development of group norms.

I also realized that I was no longer standing on my own guarding a tree but together mingling with my classmates and playing games we used to play when we were young. Even if you did not understand the game, you would just join in and make a complete fool of yourself and you will catch the rules of the game as you play. It was also fun to play games from the other races (cultural groups) as well. We mumbled some of the Afrikaans recitals but we continued playing. Not only was it fun but a wonderful experience seeing some of the white students joining in and trying to figure out all the dance moves.

It didn't matter, then, who you were standing next to or holding hands with or looking out for a familiar face to throw a ball to, because it was at that moment that we were united. We were not forced to get along, we could have chosen to remain in our little shells and comply with whatever Prof. had planned for us. The great part in all of this was 
that it expanded our knowledge and our insight on the little differences we have that we sometimes then choose to turn into big deals.

The memory of this wonderful day that opened up the children in us lives on the $10^{\text {th }}$ floor of the Human Science Building.

\section{Evadnè: What I saw was magical!}

Spring has always brought wonder to me, and every year I still stand in awe of how the dullness of winter seems to disappear within the blink of an eye when the flowers start to bloom. With age the realization came that flowers do not magically bloom when fairies sprinkle their pixie dust over the flower buds; it is a process that requires time, the right environment, and the correct climate.

I have found this wonderfully intricate process can be compared to the awareness and acceptance of diversity, and how a garden is formed by putting together different flowers; all of them beautiful in their own way. One flower does not think of competing with the one next to it, it just blooms. This year I had the privilege to see how the magical process of the coming of spring happened within our group work class.

When thinking back to before our experiential class the interaction between our students sometimes seemed to be like winter in a way, dull and cold. My metaphor might sound a bit harsh, but I have always found that I experience things in extremes and the lack of communication and division amongst students in our class broke my heart. I guess this was partially due to my belief that one can love and accept all human beings and that we are not defined by the color of our skin, but rather the condition of our hearts. In everything I do I strive to love people for their hearts, and not for their characteristics or circumstances. This notion has left me speechless, confused and disappointed many times. 
One of the exercises during our experiential class was that of creating our own garden. This was an arts and crafts activity where each student had the opportunity to paint a flower on a poster, under the shade of two symbolic trees that formed a heart. During this exercise, I had the task of assisting the other students with the paintbrushes and paint. It offered me the opportunity to observe the interaction between them whilst painting. What I saw was magical!

I was in awe with how the students started to communicate with each other. For a moment it seemed like they were playing twister, seeing how their arms intertwined, creating a space for everyone to paint their flowers. It was just as wonderful to see students who usually do not talk, laugh and complement each other on the flowers that they have painted, with numerous students also helping each other with ideas and advice on how and where to paint their flowers.

I believe that this activity and the other activities from the experiential class bonded the students, giving us the much-needed opportunity to "find" one another, leading to the realization that we were not as different as we thought we were. Every time I look at the poster of our garden or walk past it in the corridor, I remember the day spring arrived in our class and when the flowers started to bloom.

"I found a gate to that secret garden and went inside to a landscape gone amok in the most wonderful way. Where surprises spouted in every direction. Creatures collided in mid-air and fell down laughing. Colour sang and played. I felt home, and so I stayed." Aimee Myers Dolich

\section{Zipho: Previously I thought group work was about sitting and talking.}

From my perspective, group work practice has always been one-sided, monotonous and uninteresting. However, the experience in the garden changed my perspective for the 
better. We discovered that group work can be enjoyable and that the best way to understand diversity is by not only by talking about it but by having some fun while learning.

Previously I thought that group work was about sitting and talking about a certain topic, but the garden experience opened my eyes. Physical activities are very effective, relaxing and refreshing; they allow group members to get to know each other in a pleasant atmosphere. After that day, I told myself that this is how I would like my group members to feel after group work sessions with me.

Besides being fun, the activities that we did were also challenging. For example, in the first activity we had to work together as a group to lift up a "hula hoop" and bring it down. It seemed like a very simple activity but when it came to the execution, it became tricky. Within the group there were different genders and personalities; some wanted the activity to be done quick, some were too slow, a number of individuals wanted to lead and others were passive. Although this level of diversity made things complicated, it still helped us to adjust and be flexible with people who were different from ourselves.

In addition, the other activities of the day also highlighted the presence of diversity in race and culture. I learned new songs, new games and new dance moves, which was very exciting. As much as there were differences, there were similarities as well. I learned that it is helpful to have some similarities when composing a group. I realized how our similarities brought us together because there was a sense of sharing common ground.

\section{Lee-Ann: A person is a person because of people}

Desmond Tutu once said, "A person is a person through other persons. None of us comes into the world fully formed. We would not know how to think, or walk, or speak, or behave as human beings unless we learned it from other human beings. We need other human beings in order to be human. I am because other people are. A person is entitled to a 
stable community life, and the first of these communities is the family." Tutu's words of wisdom were summarized in the Zulu proverb: Umuntu Ngumuntu Ngabantu (A person is a person because of people).

My fellow students and I had difficulty grasping the full essence of the message in the beginning but after the experiential learning class we understood the proverb. It was interesting to see, once we started participating in numerous group activities, how we started to laugh, sing, dance and cry in the same language. We were no longer separated by race, language or gender. We became equal and they became one. There was one specific activity that we participated in, that is still one of my fondest memories today, it was called "There is a fire in the mountain."

We were asked to make groups of four, five, ten and even twenty people. We then had to run and grab hold of one another in order to form these groups. Without hesitation we started to run towards one another without thinking about race, gender or home language for one second. Not only did we gather more knowledge about different activities we can use during group work interventions but we acquired the ability to communicate in one language without barriers. I remember looking around at my fellow classmates noticing that not one student was without a smile.

The activities were filled with third year Social work students laughing, playing and getting to know one other better. Previously in the classroom, the students were fairly disconnected from one another, but on that specific day, Prof. Prinsloo made it possible for us to connect with one another regardless of our race, home language or gender. I recall that the activities required us to listen to each other, work together and to encourage one another when we were completing group activities. 
On that day I gained a lot of respect for my fellow classmates and realized that we should all be working together in order to make the world a better place. I now understand the importance of embracing the uniqueness of each individual. Yes, diversity is what makes us different, but diversity can help us look at the problem from different perspectives, which will help us to intervene in the best possible way in order to empower our clients and motivate change.

On that day I became a different person. Although I started the day filled with my own perspectives and ideas, I finished the day as a person who recognized the importance of diversity, along with the uniqueness of each individual. Experiential learning creates the opportunity for us to see that group work interventions can be enjoyable and fun and can help to eliminate barriers between fellow group members.

\section{Thato: I felt a certain level of closeness to my classmates}

Socialization groups help members learn how to get along and do what is socially acceptable while educational groups help members learn new information and skills. Socialization and educational groups are used in a variety of setting including treatment agencies and schools.

On this particular day we, as students, were part of a socialization group which was also educational. The purpose of this team-building day was to equip us with new information and skills about how to approach group work as a treatment method in social work, at the same time we get to know each other. Part of the purpose of both types of groups is to address needs and challenges faced by group members.

During the past two years, I attended class with people I did not see as possible friends but only colleagues. I felt excluded, bored and alone most of the time in class. This was because I thought I was older than the classmates were and had been at the university 
longer than most of them. This resulted in me feeling that I had nothing in common with them and could not form friendships with them. I saw them as colleagues and people I went to class with only.

The group work team-building day was a very fun, educative and eye opening experience for me. We had so much fun working together to accomplish goals. While executing the activities planned for the day, I learned about the similarities between my colleagues, their personalities and the type of people they are (as well as myself). I made new friends among the group members (classmates).

This experience not only changed the way I view my classmates but it changed the manner in which I approach learning as a whole. After the team-building day, I felt a certain level of closeness to my classmates. This experience also improved the way I approach group work with my group members at CR Swart high school. It gave me new and innovative ideas of how I can help and make my group work fun and enjoyable and benefiting the groups I work with socially and emotionally.

During one of the activities we were asked to draw ourselves as flowers in the garden. I realized how unique each flower was, expressing its different qualities and characteristics that make it beautiful through art and color. This represented how unique and diverse we are as students. The garden contributes to our development by giving us necessary nutrients to make sure we grow to be beautiful flowers. Together as flowers, our uniqueness (different characteristics and contributions to this garden) make this garden look extremely beautiful.

We became closer to each other, learned to accept and respect each other's differences and uniqueness, cultures and beliefs. We also became close by learning about the practices and games that influenced our ways of life. We helped each other to achieve 
tasks through communicating and learning about our roles in the group. Group work can be fun while we learn!

\section{CONCLUSION}

The universe is unique; the world is filled with differences; minds think in different ways; colors split us; languages separate us; history divides us. Yet coming together and bridging divides bring sunshine and smiles and acceptance. This experiential class aimed to bring a divided group of senior social work students together. The class aimed at a concrete experience of what it means to be a group member and to experience the dynamic process of becoming one group, regardless of individual differences. Would the key to addressing judgment and discrimination be planned exercises where people be taken back to childhood, fun, laughter and games? And then continuously reflecting on what is happening? My answer to this is: Yes! Not only have I witnessed transformation but the students reflected in their feedback how they became one unit, yet did not lose any of their individual characteristics and uniqueness.

Everyone smiles in the same language.

Unknown.

\section{Reference}

Desmond Tutu. (2015).

Retrieved from https://www.goodreads.com/author/quotes/5943.Desmond_Tutu 